\title{
Implantando a Gestão de Serviços de TI: uma abordagem horizontal baseada no catalogo de serviços de TI
}

\author{
Jeime Nunes de Andrade', Hermano Perreli de Moura² \\ 12 Centro de Informática - Universidade Federal de Pernambuco (UFPE) \\ Caixa Postal 50.732-970 - Recife - PE - Brasil \\ $\{$ jna, hermano\}@ cin.ufpe.br
}

\begin{abstract}
The importance acquired by the Information Technology (IT) for companies today, force better management of the IT in organizational environment seeking strategic alignment between IT and the business of the organization. The ITIL is a library of best practices for the management of IT services that has been used for various public and private companies that intended to improve the quality of IT services, putting them in line with the goals of the organization. However there are still many difficulties to adoption of these practices and introduce them into day-to-day organizations. The purpose of this paper is to discuss the implementation of best practices for management of IT services and to introduce a horizontal approach to deployment of the practices of ITIL based on the catalog of services of the organization.
\end{abstract}

Resumo. A importância adquirida pela Tecnologia da Informação (TI) para as empresas atuais, obriga uma melhor gestão da TI no ambiente organizacional buscando o alinhamento estratégico entre a TI e o negócio da organização. O ITIL é uma biblioteca de boas práticas para gestão dos serviços de TI que tem sido utilizado por diversas empresas públicas e privadas que objetivam melhorar a qualidades dos serviços de TI, colocando-os em conformidade com os objetivos da organização. No entanto ainda há muitas dificuldades para adoção dessas práticas e como introduzi-las no dia-a-dia das organizações. O objetivo deste artigo é discutir a implantação de boas práticas para gestão de serviços de TI e apresentar uma abordagem horizontal de implantação das práticas do ITIL com base no catálogo de serviços da organização.

\section{Introdução}

Nos últimos anos a informática deixou de ser uma simples forma de automatizar tarefas e passou a ser um instrumento de vantagem competitiva para as empresas. O papel atual da informática para as empresas e sua intensa relação com as informações empresariais gerou um novo conceito de tecnologia, conhecida como Tecnologia da Informação - TI.

De acordo com SOUZA (2004) a TI engloba os computadores de diversos tipos e tamanhos (dos mainframes aos palmtops), os sistemas operacionais necessários ao funcionamento dos computadores, as linguagens de programação, os aplicativos de automação de escritório, as tecnologias de armazenamento de dados (os sistemas de banco de dados e os sistemas de armazenagem física de dados) as tecnologias de comunicação de dados (redes de pequena e longa distância e toda tecnologia envolvida nessas redes, redes sem fio, a internet), bem como dispositivos relacionados à coleta (leitores de código de barra, câmeras digitais, scanners) e distribuição de informações digitais (terminais de vídeo painéis eletrônicos, alto-falantes). 
A integração da tecnologia da informação ao processo organizacional é um fator crítico para a execução das estratégias de uma organização (MARTINS et al, 2003). Para isso, softwares e demais ferramentas computacionais precisam se adequar aos objetivos organizacionais, às regras de negócio, às restrições e a aspectos nãofuncionais.

A TI não se restringe a equipamentos (hardware), programas (Softwares) e comunicação de dados. Existem tecnologias relativas ao planejamento de informática, ao desenvolvimento de sistemas, suporte a software, aos processos de produção e operação, e suporte ao hardware (SILVA \& OLIVEIRA, 2004).

Segundo BENZI et al (2006) para ter uma utilização plena e eficaz da TI é preciso primeiro controlar para poder gerenciar a TI, e então torna-la veículo para agregar valores aos produtos e serviços da organização. Essa é uma das principais preocupações da Gestão de TI que visa colocar a TI como fator estratégico aos negócios da organização. Empresas têm implantado modelos de Gestão de TI para melhor administrar sua estrutura computacional e aproveitar ao máximo os benefícios que a TI pode oferecer para suas estratégias de negócio e para integração interna e externa à organização.

Este trabalho tem como objetivo especificar um processo para implantação de práticas ITIL para gerenciamento de serviços de TI, avaliando inicialmente alguns fatores organizacionais considerados críticos para o projeto e definindo uma abordagem de implantação, de acordo com os serviços prestados pela organização.

\section{Gestão de TI}

À medida que a TI ganhou importância para as organizações, cresceram também os investimentos destinados a este setor das empresas. No ambiente empresarial, para todo investimento é esperado retorno, seja direto ou indireto, e na área de TI não é diferente. Esse retorno sobre os investimentos é um dos desafios da gestão de TI.

A Gestão de TI é um processo estruturado para gerenciar e controlar as iniciativas de TI nas organizações, para garantir o retorno de investimentos e a adição de melhorias nos processos empresariais (FAGUNDES, 2004). SORTICA et al (2004) acrescenta que a TI é um fator essencial para a gestão financeira e estratégica de uma organização e não apenas como suporte à empresa.

A gestão de TI busca governar a área de TI de forma que agregue valor aos negócios da organização. BENZI et al (2006) afirma que organizações com a gestão de TI ajustada ao negócio, com foco no tratamento adequado da informação, têm suas ações facilitadas no intuito de aproveitar as oportunidades e correm menos riscos diante das ameaças potenciais.

A adoção de um modelo de gestão de TI eficiente, pode ser auxiliado por boas práticas e frameworks disponíveis no mercado, tais como COBIT, ITIL, PMBOK, CMMI, Six Sigma, etc, (FERNANDES \& ABREU, 2006). A escolha do modelo fica a critério das necessidades e dos problemas que precisam ser corrigidos na organização. No entanto para implantar um modelo de gestão de TI e para que a própria gestão de TI obtenha sucesso é necessária uma avaliação do ambiente organizacional onde a gestão de TI será implantada e executada, observando os fatores que podem influenciar no trabalho. 


\section{ITIL}

A Information Tecnology Infrastructure Library (ITIL) fornece um conjunto coerente e compreensivo de melhores práticas para gestão de serviços de TI, provendo qualidade técnica para realizar negócios com eficiência e efetividade no uso de sistemas da informação. As práticas do ITIL são baseadas na experiência de empresas comerciais e governamentais de todo o mundo, as quais têm se tornado cada vez mais dependentes de TI (OGC am, 2003).

A ITIL foi desenvolvido na década de 1980 pelo Office Government of Commerce Britsh - OGC, inicialmente como um guia do governo britânico para gestão de serviços. Com suas evoluções, a ITIL se tornou um padrão britânico, através da norma PD0005, e atualmente é parte da norma ISO 20000, um padrão internacional para gestão de serviços de TI.

A figura 01 mostra o escopo do framework ITIL, que possui sete domínios e a representação da gestão de serviços como ponto central do framework. O framework ITIL tem o propósito de fornecer uma integração entre a TI e os objetivos de negócio da organização, através de um gerenciamento da estrutura e do fornecimento e suporte dos serviços de TI.

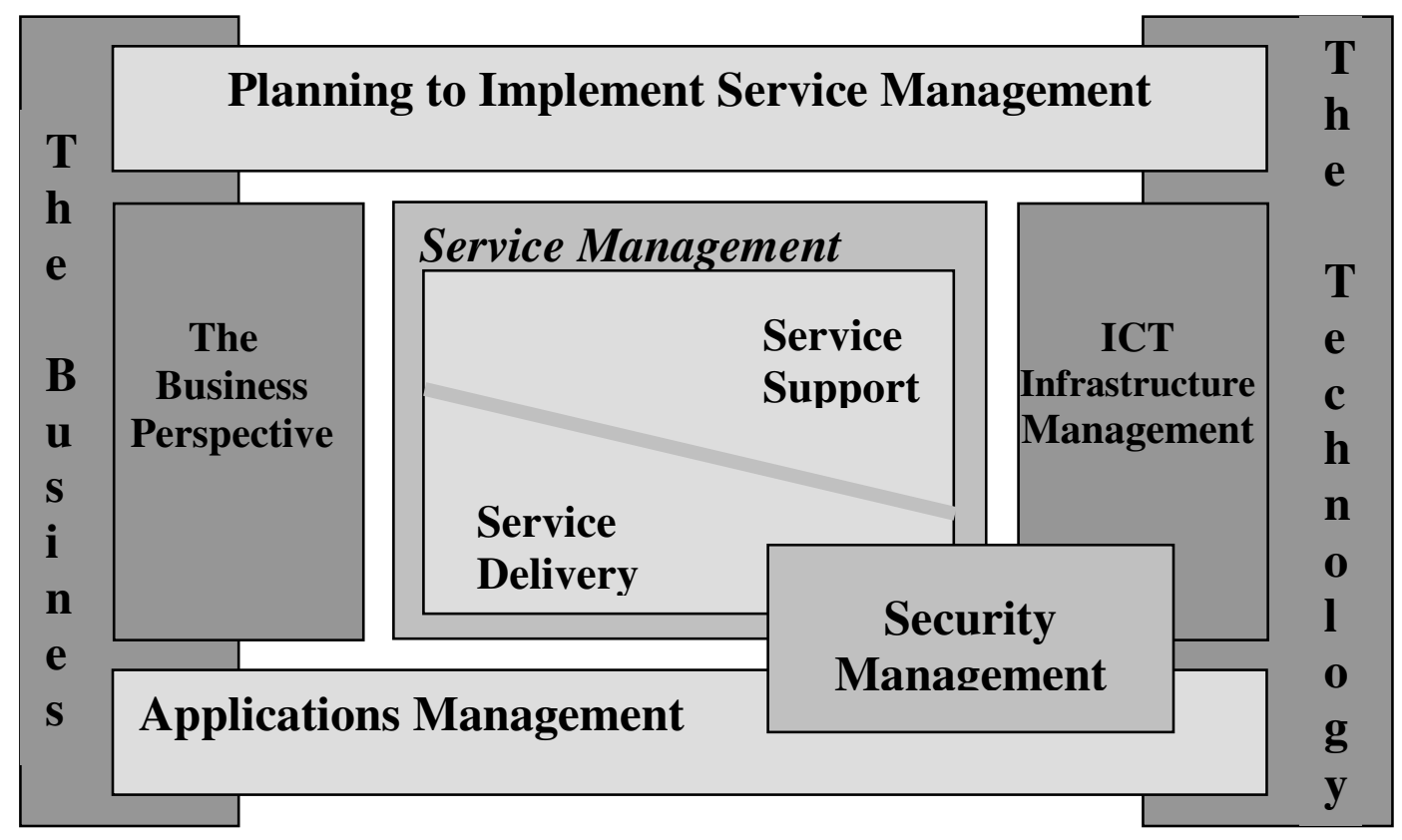

Figura 01: Estrutura do framework ITIL (OGC am, 2003).

O framework apresentado se divide em domínios, e para cada um deles há um livro publicado pela OGC. O "Planning To Implement Service Management" orienta como planejar a implementação do ITIL alinhando as estratégias de TI com as estratégias do negócio. A "ITC Infrastructure Management" fornece uma infraestrutura de TIC estável através de ferramentas, serviços de rede, etc. A "Applications Management" gerencia aplicações e o desenvolvimento destas, sob uma perspectiva de gerenciamento de serviços. "The Business Perspective" estabelece a relação entre os requisitos e negócios organizacionais com o fornecimento de serviços de TI (Gestão de relacionamento, terceirização, etc). A "Security Management" gerencia 
confidencialidade, integridade e disponibilidade de serviços de TI com custos aceitáveis.

O "Service Delivery" é a porta de contato com o cliente contratante dos serviços e trata da manutenção e melhoria da qualidade dos serviços que são oferecidos com o foco na satisfação do cliente. É composta por cinco processos (OGC sd, 2003):

- Capacity Management (planejamento da capacidade e gerenciamento das demandas);

- Financial Management (sustentação econômica dos recursos de TI);

- Availability Management (garantir o nível de disponibilidade dos serviços de TI);

- Service Level Management (gerenciar, manter e melhorar a qualidade dos serviços de TI);

- Service Continuity Management (determinação das necessidades de TI para os negócios da organização);

O "Service Support" é a porta de contato com o usuário dos serviços contratados e assume os problemas da infra-estrutura e preocupa-se evitar que eles ocorram. É composto por uma função e cinco processos (OGC ss, 2003):

- Service Desk (é uma função com atendimento direto a usuários, gerencia, coordena, resolve incidentes e acompanha solicitações);

- Incident Management (restaurar serviços o mais rápido possível);

- Problem Management (prevenir e investigar a causa dos incidentes, minimizando os impactos);

- Configuration Management (identificação, controle, manutenção e auditoria de Itens de Configuração);

- Change Management (padronização de métodos e procedimentos para mudanças no ambiente computacional);

- Release Management (garantir que aspectos técnicos e não-técnicos sejam considerados nas mudanças, bem como o planejamento dos recursos envolvidos);

\section{Fatores críticos para gestão de serviços de TI}

Albertin (2004) utiliza uma organização de fatores críticos para a administração da informática, agrupando esses fatores em quatro categorias: fatores críticos da função planejamento, fatores críticos da função organização, fatores críticos da função pessoal, fatores críticos da função direção e fatores críticos da função controle.

Por exercerem grande influência na implantação e execução de um modelo de gestão de TI esses fatores serão abordados nesse trabalho como forma de avaliação das condições do ambiente organizacional para o projeto de implantação de processos do ITIL para gestão de serviços de TI. Segundo PASQUALETTO \& MEZZOMO (2006) esses elementos organizacionais são profundamente relacionados com os objetivos da gestão de serviços de TI.

\subsection{Fatores críticos de planejamento}

Planejamento por si só já é um fator indispensável para o sucesso de qualquer operação. No entanto ainda é uma grande deficiência nos projetos de TI. Podemos considerar como principais fatores dentro da função planejamento:

\section{- Apoio da alta gerência;}


$\mathrm{O}$ relacionamento entre a alta gerência da empresa e o setor de TI precisa ficar em equilíbrio e coerência. $\mathrm{O}$ comprometimento e a visão da alta gerência com o setor de TI é decisivo em questões relacionadas com o gasto em TI, difusão da TI na empresa, qualidade dos serviços de TI e os riscos envolvidos com TI. Essas questões definirão o valor da TI para o negócio da organização.

- Alinhamento estratégico;

O alinhamento estratégico entre a TI e a organização é o fator que garante a coerência nas estratégias, prioridades e estrutura organizacional. Esse alinhamento define uma área de TI para todo o ambiente organizacional e sua relação com o ambiente externo.

\section{- Processo de priorização;}

É um fator crítico totalmente baseado no alinhamento estratégico, e se baseia em fatores como: objetivos de negócio, estratégias de negócio, benefícios financeiros, benefícios intangíveis, entre outros. O sucesso da priorização depende do nível de interação entre os altos executivos, usuários e gerentes de TI.

\section{- Processo de estimativa;}

Outro fator importante do planejamento é ter um processo de realização de estimativas sobre os esforços e recursos envolvidos nos projetos. As estimativas contribuem para a análise de viabilidade e elaboração de projetos confiáveis.

\subsection{Fatores críticos de Organização}

Na função de organização existe uma preocupação com a proximidade da TI com a organização, ou seja, um relacionamento mais próximo entre a informática e as áreas usuárias. Esse relacionamento é definido de acordo com a estrutura organizacional e a participação da TI na organização.

- Estrutura organizacional;

É importante o estabelecimento de uma estrutura organizacional bem definida em níveis de responsabilidades, atribuições, canais de comunicação, de forma a facilitar a aquisição, assimilação, disseminação e utilização de novas tecnologias.

\section{- Participação na organização;}

Esse fator traduz na proximidade da área de TI com áreas usuárias e com o ambiente do negócio da organização. Essa participação busca uma postura da TI voltada para o negócio e não apenas para assuntos técnicos. É importante dar a TI uma visão do mercado e dos clientes da organização, e usa-las para especificação de soluções aos problemas reais enfrentados pela organização.

\subsection{Fatores críticos de Pessoal}

Os aspectos gerenciais e sociais já são percebidos como críticos no setor de TI, mas os aspectos técnicos continuam tendo mais relevância. O pessoal da TI precisa ter competência na tecnologia utilizada e também adquirir competências nas novas, mas atualmente exige-se uma postura voltada para o negócio da organização e os aspectos sociopolíticos. 
- Aspectos sociopolíticos;

A gestão de TI é uma atividade altamente política, onde o pessoal envolvido deve se preocupar em contribuir para a organização. É necessário manter constantes contatos com os usuários e aprender a administrar o trabalho que vem sendo realizado.

\section{- Novas tecnologias;}

Fator que exige um domínio, mínimo que seja, de novas tecnologias para possibilitar que a área de TI ofereça à organização soluções mais ágeis e coerentes com sua realidade. A aquisição e implantação de novas tecnologias devem ser feito de forma coerente com as áreas usuárias para minimizar as dificuldades e evitar possíveis rejeições.

\subsection{Fator crítico de Direção}

$\mathrm{Na}$ função direção há uma preocupação com as gerencias de nível médio e sua deficiência de formação devido a pouca preparação de seus participantes para assumir posições gerenciais.

\section{- Gerência de TI;}

Dentro da função direção o principal fator é a Gerencia de TI, e sua preparação e participação nos processos da organização. Os gerentes de TI precisam exercer funções de negócio, de gerentes e de tecnologistas. Portanto na função de negócio precisam ser articuladores, ter boa comunicação, ser educados e ter bom conhecimento sobre os negócios da organização. Como gerentes devem gerenciar pessoas, orçamentos e projetos. Como tecnologistas devem entender de diversas tecnologias e como elas se interagem, estar atualizados com as tendências tecnológicas e sempre que necessário utilizar-se de assessorias técnicas para gerenciar as tecnologias sofisticadas.

\subsection{Fator crítico de Controle}

$\mathrm{O}$ controle em projetos de TI tem sido mais exercido em atividades estruturadas e mais operacionais, e ainda é bastante deficiente em atividades não tangíveis e menos operacionais. Considerando uma visão bem abrangente o controle de desempenho e qualidade é o fator crítico do controle.

\section{- Controle de desempenho e qualidade;}

Os projetos de TI também devem ser acompanhados e avaliados utilizando esses controles de desempenho e qualidade das atividades e produtos envolvidos nos projetos. Por isso é preciso ter critérios não técnicos, como satisfação de usuários e clientes, adequacidade, nível de utilização. Os controles precisam ser claros e que não se tornem obstáculos para o desempenho das atividades.

\section{Um processo para implantação das práticas ITIL}

Em pesquisa realizada pelo ITSMF Brasil (2006), capitulo brasileiro do Fórum Internacional de Gestão de Serviços de TI, foi verificado que 58\% das empresas pesquisadas utilizam as práticas do ITIL, porém de forma aleatória. Apenas $20 \%$ dessas trabalham com programas formais do ITIL. Uma dos motivos apontados para a informalidade é a dificuldade de adaptação do ITIL às necessidades da empresa. 
Ao iniciar um projeto de adoção das práticas do ITIL é comum esbarrar em alguns questionamentos: "por onde começar", "como começar", "o que é necessário fazer", "como planejar". Como esclarecido por Fontes (2007), as respostas a estas questões estão sujeitas a vários fatores da organização em causa. No entanto, o processo especificado nesse trabalho tenta criar orientações de como planejar e executar fases e atividades, que facilitem a adoção das boas práticas de gestão de serviços de TI especificadas no ITIL, através dos domínios do Service Support e Service Delivery. Esse processo está dividido em 4 fases, as quais são divididas em atividades.

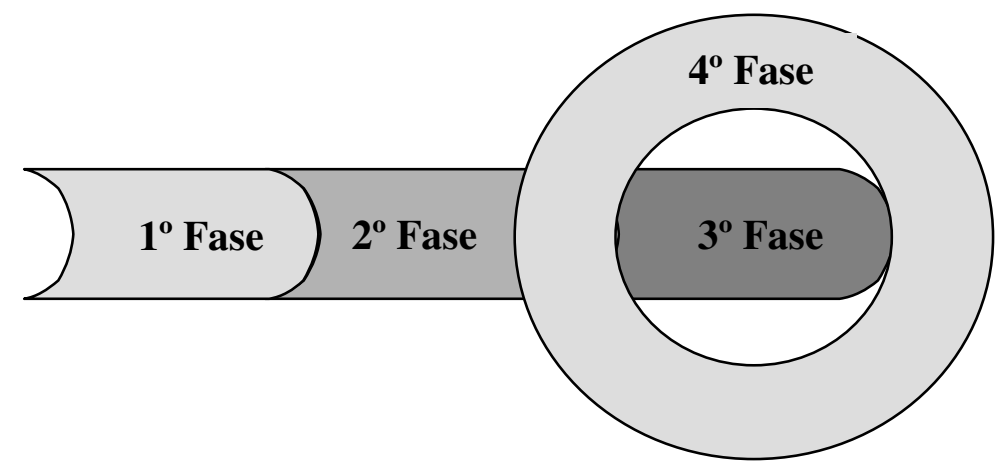

Figura 02: Representação do Processo de Implantação

$\mathrm{Na} 1^{\circ}$ Fase é definido o Catalogo de Serviços de TI da organização, que será a base para as outras fases. A $2^{\circ}$ Fase é dedicada ao planejamento do Projeto de Implantação, através de 4 macro atividades. A $3^{\circ}$ Fase é a adaptação e implantação das práticas de gerenciamento de serviços de TI do Service Support e Service Delivery do ITIL. A $4^{\circ}$ Fase é uma evolução contínua do gerenciamento dos serviços de TI, bem como o constante alinhamento entre TI e negócios.

\subsection{Primeira fase: Definição do Catálogo de Serviços}

O principal propósito do catalogo de serviços é documentar os serviços de TI e estabelecer a base para outros componentes de gerenciamento de serviços, se tornando também a base para documentação de procedimentos e processos de TI da organização (WARD, 2004). O catalogo de serviço é uma ferramenta primária para definição de uma estrutura organizacional de gestão de serviços de TI, e será a base para as próximas fases e atividades desse processo de implantação.

A definição do catalogo de serviços é iniciada identificando primeiro os serviços de TI que são críticos para os objetivos de negócio da organização, os quais fornecem suporte às atividades relacionadas com esses objetivos de negócio. Esse momento é a oportunidade de verificar se a TI exerce um papel importante nos negócios da organização, ou se ocupa apenas uma função de apoio. $\mathrm{O}$ resultado dessa verificação mostrará possíveis necessidades de modificações nas atuações da TI dentro da organização.

Em seguida são identificados os serviços que não tem relação direta com os objetivos de negócio. São serviços que apóiam as atividades administrativas dos clientes e serviços de suporte geral da organização. Os serviços podem ser divididos em subserviços, e é aconselhável que sejam definidos considerando a visão e entendimento dos clientes.

Após a definição dos serviços, para cada serviço é definida as seguintes informações: 
- Nome do serviço:

- Descrição do serviço:

- Ponto de contato para suporte:

- Gerente responsável:

- Clientes/Usuários:

- Informações detalhadas: infra-estrutura, disponibilidade, produto final, etc.

\subsection{Segunda fase: Planejamento para o projeto de implantação}

Uma boa técnica para implantação das práticas do ITIL é gerenciar o trabalho como um projeto, ou até vários projetos de implantação dos processos. Nesse projeto é importante estar definida a situação atual da gestão de serviços e até que ponto se pretende chegar, traçando os possíveis caminhos entre esses dois estados (OGC pism, 2003). Para cada caminho avalia-se: os benefícios para o negócio; os riscos, obstáculos e problemas potenciais; e em pontos estratégicos avaliar os custos de continuar ou mudar a estrutura corrente.

\subsubsection{Avaliação do ambiente organizacional}

Antes de começar a implantação das práticas é importante realizar uma avaliação do ambiente organizacional, para ter um entendimento dos custos atuais relacionados aos serviços e assim avaliar os impactos da melhoria dos processos de gestão de serviços. Esse estudo inicial é importante até mesmo para definir se o ITIL é a ferramenta mais adequada para resolver os problemas existentes no fornecimento de serviços de TI da organização.

A avaliação organizacional será realizada com base nos Fatores Críticos de Sucesso para a Gestão de TI, abordados no item 4 e seus subitens. Essa avaliação permitirá a identificação de riscos para o projeto, pontos positivos, os desafios a serem enfrentados, além de dar uma idéia geral das dificuldades para execução das atividades. A avaliação desses fatores mostrará como está a relação entre a TI e os clientes.

Como parte desse levantamento organizacional pode-se aplicar uma pesquisa de opinião com clientes e usuários, sobre a satisfação e qualidade dos serviços prestados pela área de TI, bem como sugestões de melhoria.

\subsubsection{Divisão do projeto geral em subprojetos}

A adoção das práticas do ITIL trará possíveis modificações na organização. A definição e ajustes nos processos operacionais possivelmente modificarão o ambiente técnico e à forma como as pessoas executam seus trabalhos, causando resistências e dificuldades ao projeto de implantação. O tamanho da organização, abrangendo aqui número de funcionários, setores, quantidade de hardware e software, e a quantidade de serviços de TI influenciam diretamente nas diferentes variáveis do projeto (tempo, custo, risco, recursos, etc).

Buscando facilitar o trabalho e minimizar as dificuldades, o projeto geral de implantação deverá ser dividido em subprojetos. A base para formação dos subprojeto será o catalogo de serviços definido na Primeira Fase. Cada subprojeto abordará um serviço, ou conjunto de serviços/subserviços relacionados, para o qual será aplicada as práticas de gestão de serviços de forma horizontal. Ou seja, para cada subprojeto será definido um processo operacional o qual evolutivamente entrará em conformidade com as boas práticas do ITIL, especificamente do Service Support e Service Delivery. 


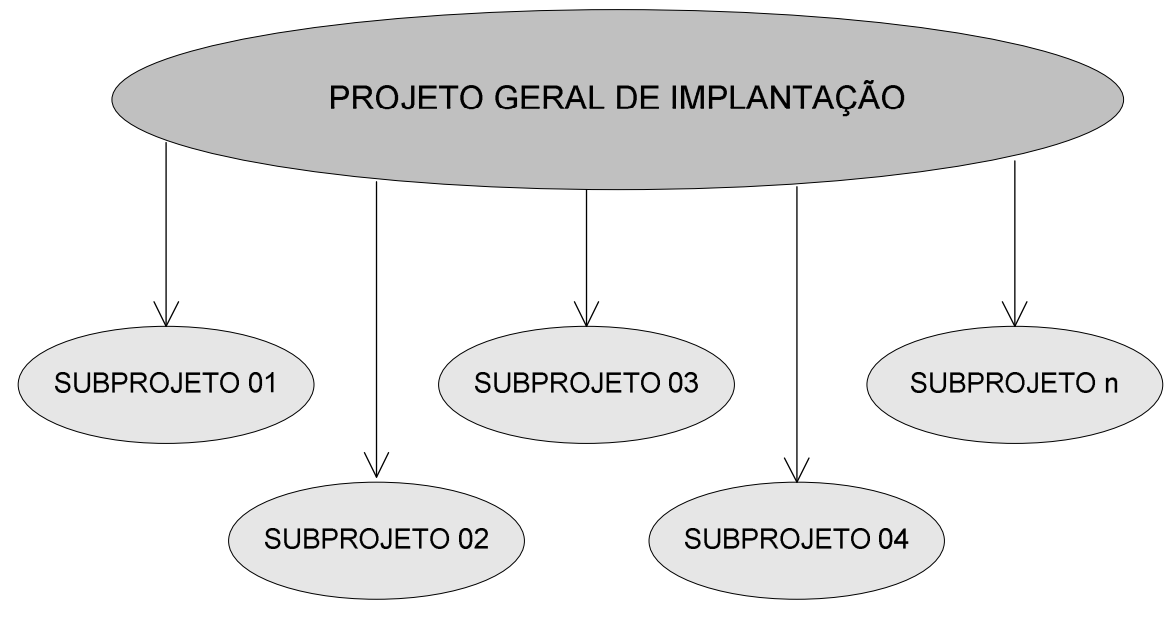

Figura 03: Divisão do projeto geral em subprojetos

\subsubsection{Priorização dos subprojetos}

Dependendo da quantidade de serviços de TI existente, a execução dos subprojetos pode se estender por meses e os diferentes stakeholders estão ansiosos pelos resultados que mais lhes interessam. Diante de tantas expectativas, muitas vezes divergentes, é importante definir prioridades para os subprojetos, considerando nessa atividade as seguintes variáveis:

- Criticidade dos serviços para o negócio da empresa;

- Serviços em situações mais precárias de gestão e qualidade;

- Preferências dos stakeholders;

- Unidades envolvidas;

- Disponibilidade de recursos;

Possivelmente ocorrerá conflitos após a análise das variáveis acima. Isso exigirá da equipe de implantação um pouco de habilidades para resolvê-los, ou ao menos minimizar-los, de forma a não prejudicar os andamentos dos trabalhos.

\subsubsection{Criação de um Plano de Projeto para o subprojeto a ser executado}

Os subprojetos são partes do projeto geral e devem ser gerenciados como tal. Assim é importante ter controle e gestão sobre as atividades que serão realizadas durante esse subprojeto, utilizando-se de um Plano de Projeto formal e documentado. O Plano de Projeto será a base gerencial dos respectivos subprojetos, e através do qual a equipe de implantação manterá atualizadas as informações sobre o andamento e resultado do subprojeto. Tanto o projeto geral como os subprojetos poderão ser apoiados por técnicas de gerenciamento de projetos, como as descritas no PMBOK (2004).

\subsection{Terceira fase: Execução dos subprojetos de implantação}

\subsubsection{Definição e representação de processo operacional para o serviço}

A definição do processo operacional permitirá um mapeamento de todo o ciclo de atividades para a realização do serviço, relacionando as entradas com as ações internas para gerar as saídas. Para definição e formalização do processo deve ser usado algum método formal (Workflow, UML, etc) que permita representar todas as etapas do ciclo de atividades, tornando-o conhecido por todos os envolvidos no serviço. 
O processo fornece uma visão detalhada do serviço, o que possibilita identificar pontos deficientes (gargalos) que geram atrasos e problemas na execução do serviço. Esses pontos serão o alvo de mudanças e aperfeiçoamentos no processo operacional durante a Fase 4 Melhoria Contínua do Processo Organizacional.

É possível que algum processo operacional aborde mais de um serviço, ou pelo menos um conjunto de subserviços como colocado no catalogo de serviço.

\subsubsection{Especificação e relacionamento dos recursos envolvidos no serviço}

Complemento das informações contidas no catalogo de serviços sobre os recursos utilizados/envolvidos na realização do serviço, especificando:

- Hardwares;<identificação no CMBD e limites sobre a utilização no serviço>

- Softwares: <identificação no CMBD>

- Pessoas; <Nomes, cargos, responsabilidades/funções perante o serviço>

- Empresas terceirizadas; <caso haja alguma terceirização relacionado com o serviço, especificar qual a função da terceirizada com o serviço>

\subsubsection{Implantação das práticas do Service Support e Service Delivery para o serviço}

Recomenda - se que a implementação do ITIL seja feita de forma gradual, partindo de um escopo reduzido de operações como piloto, e promovendo roll-outs sucessivos para as demais operações, respeitando sempre as interdependências existentes entre os processos de gestão e os requisitos de disponibilidade e continuidade dos serviços. Deve também ser considerada a necessidade de adoção de ferramentas específicas de automação, tais como gerenciadores de chamadas, inventário, etc, que podem apoiar total ou parcialmente as práticas do modelo (FERNANDES \& ABREU, 2006).

Após a Fase de Planejamento a equipe de implantação já terá as condições necessárias para abordarem as práticas do Service Support e Service Delivery, os principais domínios do ITIL. Ainda existem muitas discussões sobre uma seqüência ideal de abordagem das práticas desses domínios. No entanto nesse processo será utilizada a curva de maturidade dos serviços de TI representada em Mansur (2007), como a sequiência da adoção das boas práticas do Service Support e Service Delivery do ITIL, conforme representação da Figura 03 abaixo.

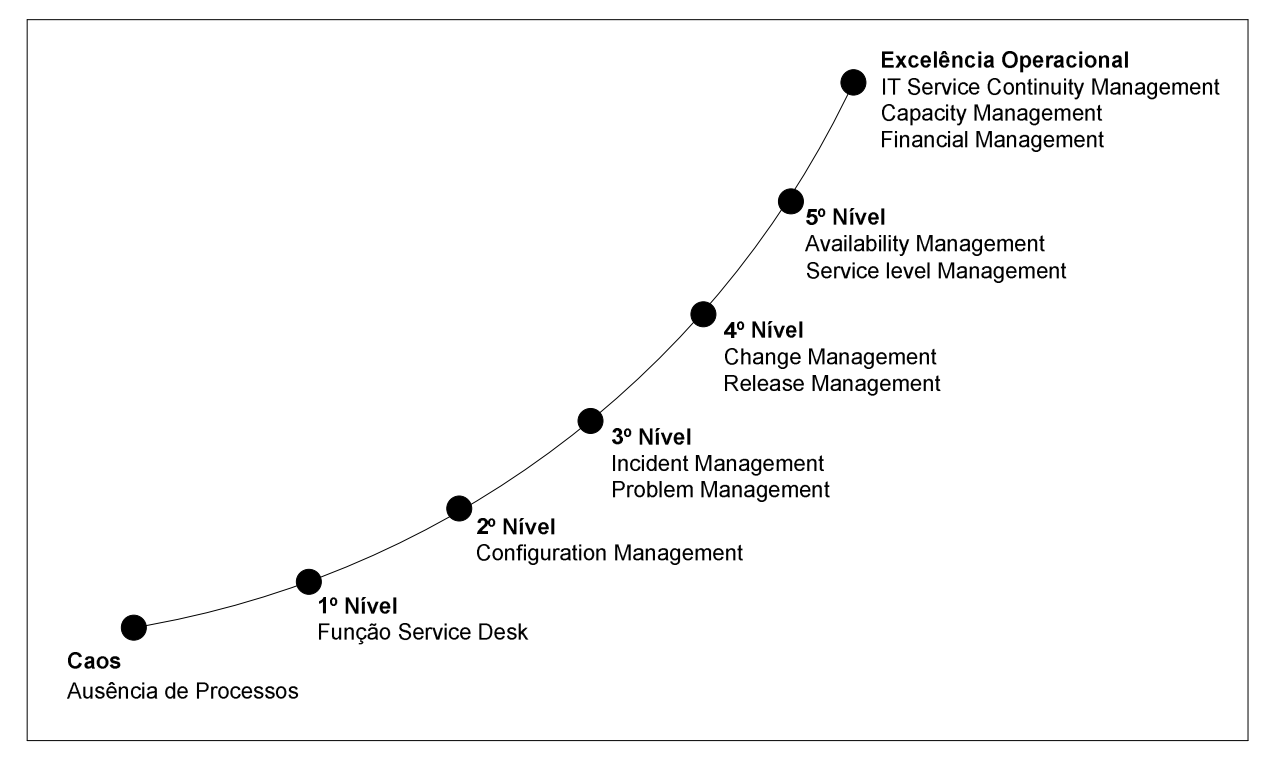


Figura 04: Curva de maturidade dos serviços de TI e seqüência de adoção das práticas ITIL nesse processo

Começar pelo Service Support é uma precaução para manter uma estabilidade e suporte operacional para os serviços de TI, antes de assumir Acordos de Níveis de Serviço com os clientes.

\subsection{Quarta fase: Melhoria contínua do processo organizacional}

A adoção das práticas do ITIL é um processo evolutivo onde as evoluções devem sempre buscar os objetivos de qualidade dos serviços. O processo operacional definido na Terceira Fase é a base para as evoluções e melhorias nos serviços, através de constantes análises e melhorias das atividades desse processo. No processo operacional ficam formalizadas as etapas e atividades do ciclo de vida do serviço, para que os envolvidos entendam e cumpram as especificações do processo.

\section{Conclusões e trabalhos futuros}

Para um projeto que visa implantar um modelo de gestão de TI, essa avaliação preliminar é decisiva na escolha do modelo mais adequado para resolver os problemas e deficiências do setor de TI da organização. Os fatores utilizados devem abranger desde critérios técnicos (ferramentas, tecnologias utilizadas, estrutura tecnológica, etc) como os critérios não técnicos (capacidade gerencial dos gerentes, apoio para o projeto, imagem da empresa frente aos clientes, etc). A implantação dos processos do ITIL gera muitas mudanças nos processos de trabalho da organização, o que exige um cuidadoso planejamento das atividades do projeto de implantação. O projeto de implantação deve seguir as necessidades mais urgentes da organização e as prioridades dos principais stakeholders envolvidos, mas considerando as relações e dependências entre os processos. As lições aprendidas com a implantação dos primeiros processos, podem ser usadas como base para a implantação dos processos seguintes, contribuindo para o sucesso do projeto geral de implantação. Através do controle sobre as atividades de TI, a gestão de TI viabiliza uma melhor qualidade dos serviços fornecidos, gera maior satisfação dos clientes e usuários, além de possibilitar uma maior contribuição da TI para os negócios da organização.

\section{Referencias}

ALBERTIN, Alberto Luiz. Administração da Informática: funções e fatores críticos de sucesso. $5^{\text {a }}$ ed. São Paulo: Atlas, 2004.

BENZI, D. M.; NETO, J. S.; ORLANDI, T. R. C.; SOUZA JR, R. T.: Governança de Tecnologia da Informação - Facilitadora na estratégia organizacional. In: SEGeT 2006 - Simpósio de Excelência em Gestão e Tecnologia, 2006, Resende-RJ. Anais do. Resende-RJ : EADB, 2006. p. 747-1-747-12.

FAGUNDES, F. M.: COBIT - Um kit de ferramentas para a excelência na gestão de TI. Disponível em <www.efagundes.com/Artigos/Arquivos_pdf/cobit.pdf $>$. Acessado em 20/12/2006.

FERNANDES, Agnaldo Aragon e ABREU, Vladimir Ferraz. Implantando a Governança de TI: da estratégia à gestão dos processos e serviços. Editora BRASPORT, Rio de Janeiro, 2006; 
FONTES, Guilherme. Passos e competências para implementar o ITIL. SINFIC, Newsletter 98. Disponível em <http://www.sinfic.org/SinficNewsletter/sinfic/ Newsletter98/ index98.html > . Acessado em 10/07/2007.

ITSMF Brasil. Adoção do ITIL no Brasil. Pesquisa realizada pelo Fórum Brasileiro de Gestão de Serviços de TI. Disponível em < http://www.companyweb.com.br/artigos/> . Acessado em 30/06/2007.

MARTINS, Gilbert Breves et al. A tecnologia da informação no processo organizacional. Revista T\&C Amazônia, Ano1, Fevereiro de 2003.

OGC am, Office of Government Commerce. Aplication Management. Reino Unido: The Stationery Office, 2003. Material disponibilizado em CD.

OGC sd, Office of Government Commerce. Service Delivery. Reino Unido: The Stationery Office, 2003. Material disponibilizado em CD.

OGC ss, Office of Government Commerce. Service Suport. Reino Unido: The Stationery Office, 2003. Material disponibilizado em CD.

OGC pims, Office of Government Commerce. Planning for the Implementation of Service Management. Reino Unido: The Stationery Office, 2003. Material disponibilizado em CD.

PASQUALETTO, Loimar e MEZZOMO, Edimara. Implantação de práticas ITIL: O caso do TRF4. Congresso Anual de Tecnologia da Informação - CATI, 2006.

PMBOK; Conjunto de Conhecimentos em Gerenciamento de Projetos. Terceira Edição, 2004.

SILVA, Ariana Falcão e OLIVEIRA, Francisco Correia. Desafios da Tecnologia da Informação no Setor Público. Congresso Anual de Tecnologia da Informação CATI 2004, FGV-EAESP.

SORTICA, E. A.; CLEMENTI, S.; CARVALHO, T. C. M. B.: Governança de TI Comparativo entre Cobit e ITIL. Anais do Congresso Anual de Tecnologia da Informação - CATI, 2004.

SOUZA, César Alexandre. Uso organizacional da TI: Um estudo sobre a avaliação do grau de informatização de empresas industriais paulistas. Tese de doutorado. Programa de Pós-Graduação em Administração. Universidade de São Paulo. 2004.

WARD, Janice; How to build a service catalog. Disponível em $<$ http://techrepublic.com.com/ >. Acessado em 10/06/2007. 